\title{
Imperatives as semantic primitives
}

\author{
Rosja Mastop
}

Published online: 14 January 2012

(C) The Author(s) 2012. This article is published with open access at Springerlink.com

\begin{abstract}
This paper concerns the formal semantic analysis of imperative sentences. It is argued that such an analysis cannot be deferred to the semantics of propositions, under any of the three commonly adopted strategies: the performative analysis, the sentence radical approach to propositions, and the (nondeclarative) mood-as-operator approach. Whereas the first two are conceptually problematic, the third faces empirical problems: various complex imperatives should be analysed in terms of semantic operators over simple imperatives. One particularly striking case is the Dutch pluperfect imperative. It is argued that this construction should be analysed as a genuine counterfactual imperative. On the constructive side, in the last part of the paper a formal semantic analysis of imperatives is presented, in the framework of Update Semantics. On this analysis, imperatives are sui generis semantic entities, on a par with propositions. The analysis also includes an account of the counterfactual imperatives.
\end{abstract}

Keywords Imperatives · Philosophy of language - Update semantics · Counterfactuals $\cdot$ Free choice

\section{Introduction}

There are three different ways in which nondeclaratives have been integrated into truth conditional theories of meaning. These are: the performative analysis, which treats them as explicit or modal performatives and regards them as simply true or

R. Mastop (西)

Utrecht University, Janskerkhof 13A, 3512 BL Utrecht, The Netherlands

e-mail: rosja.mastop@phil.uu.nl 
false; the parametric analysis, according to which any meaningful expression is a molecular compound of two independent components, one for the sentence type or force $F$ and one for the content 'sentence radical' $p$; and the operator analysis, according to which nondeclarative semantic operators $F$ transform a proposition $p$ into a nondeclarative semantic entity. The difference between the second and third approaches seems small, but whereas in the second approach the distinction between sentence type and content marks the distinction between conversational pragmatics and representational content, the third approach analyses nondeclaratives completely within the semantic realm. Still, both are reductionist accounts, insofar as they consider (de)compositional semantics as dealing exclusively with propositional content-although in the operator analysis nondeclarative operators can be added in a last step. The idea that binds these three accounts of imperatives is that the intuitive connection between declaratives and imperatives, as in (1), must be explained by reference to a shared semantic entity contained in an analysis of those sentences.

\section{(1) a. Ann closes the door.}

b. Ann, close the door.

A fundamental idea of formal semantics is that the semantic value of propositions (expressed by means of simple indicatives) is primitive. In classical semantics propositions are simply true or false (at worlds or indices), and in dynamic semantics propositions are atomic information units or context change potentials. Any compositional or decompositional semantic analysis of indicatives begins with the primitive semantic values of propositions. Here I want to propose that we treat instructions (expressed by means of simple imperatives) as semantic primitives, on a par with propositions: instructions are directive messages, just as propositions are informative messages. Both may be analysed by functional decomposition into (indicative/imperative) verb-meanings and noun-meanings, but imperative force is not a component from which we can abstract, retaining a propositional content. Any compositional or decompositional semantic analysis of imperatives has to start with the basic semantic value of instructions.

To avoid confusion, I should preliminarily contrast this semantic conception of imperatives with a pragmatic one. The latter would equate the imperative with a speech act type such as commanding, advising or requesting, or a bundle of these. It is a commonplace to analyse, e.g., 'that' clauses as expressing propositions, despite the fact that they are not as such used to make a statement. The semantic value of the 'that' clause is the informative content it would have when used standalone in making an assertion. A similar argument was offered in favour of the semantic view of interrogatives Groenendijk and Stokhof (1984): 'wh' clauses are analysed in terms of interrogative semantics, despite the fact that they are not as such used to ask a question. The semantic value of a 'wh' clause (at least in the context of a verb such as 'wonder') is the interrogative content it would have when used standalone in asking a question. Here, the term 'instruction' will be used for the semantic content of a standalone imperative utterance. Instructions may, in principle, also be the contents of clauses other than what we normally call imperative sentences. Perhaps 
certain types of infinitival clauses can be analysed as embedded instructions (that will not be argued for here, but see Huntley (1984) and Portner (1997) for support of this idea). In that case the infinitival clause will be assigned the semantic value of the instructional content it (the corresponding imperative) would have been when used standalone, e.g., in issuing a command.

There is a critical element and a constructive element to the proposal of this paper. The critical element is the rejection of all attempts to reductively analyse imperatives in terms of a propositional semantics and a pragmatics of mood. ${ }^{1}$ Imperatives should be analysed in terms of a distinctive imperative semantics, not divided into separate layers or components. The only pragmatics there is to imperatives concerns the question why a speaker decides to use a particular imperative at a particular occasion, just as in the Gricean pragmatics of conversation. The constructive element of the proposal concerns the identification and compositional analysis of complex imperatives. In this paper we will only be concerned in detail with one such case: the embedding of imperatives under a counterfactual or 'irrealis' modality. I will argue that Dutch has such a construction and I will propose an analysis of this construction in terms of update semantics.

In the first three sections, I will develop the critical element of the proposal, by criticising the aforementioned three different ways in which imperatives have been reductively analysed in the literature. The first two of these are argued to face conceptual problems. The third acknowledges imperatives as an independent semantic category, but adds an empirical claim that they can be analysed uniformly in terms of operator and proposition. This empirical claim so far remains largely unfounded. I will discuss some complex imperative constructions that seem illsuited to the operator-proposition analysis: conditional, negated and disjunctive imperatives, quantified imperatives, first and third person imperatives and counterfactual imperatives. The empirical data on which this argument is based are taken from Dutch.

In the sections thereafter, I will develop the constructive element of the proposal. This includes: a brief explanation of the conceptual underpinnings of the semantic framework, a presentation of an update semantics for propositions and instructions, and an analysis of counterfactual imperatives in terms of that update semantics. In this second part I cannot deal with all the cases of complex imperatives discussed in the first, critical part. The aim here is not to present a full-fledged semantic theory of imperatives, but to develop a new approach for doing semantic analysis of imperatives, and show by means of an example that it is a sound and fruitful approach.

\section{The performative analysis}

The performative analysis has been largely abandoned since its inception in the 1970s, although some versions of it are still implicit in contemporary generative grammar [perhaps Han (1999) and Platzack and Rosengren (1998) are examples].

\footnotetext{
1 See also Hamblin (1987) for a criticism of reductionism in the semantics of imperatives.
} 
Recently, Schwager (2006) has defended what can be considered as a version of this view.

Performatives can be categorised into those that are and those that are not explicit about the communicative act that is performed by uttering them. As for commands, this means that we may distinguish between (2-a) and (2-b).

(2) a. Shut the door.

b. I order you to shut the door.

Both are performative, but the latter is an 'explicit performative', because its main verb explicitly indicates what the speaker is doing when uttering the sentence. Besides explicit performatives we may also identify modal performatives, such as (2-c), that can be used for the same conversational task as the previous ones.

c. You (should/will) shut the door.

There are sometimes practical reasons for using explicit performatives: a simple sentence like (2-a) may fail to communicate whether the speaker is commanding, advising, requesting and so on. I think Austin explained the relation between the two correctly:

'I order you to shut the door' would be an explicit performative utterance, whereas 'Shut the door' would not-that is simply a 'primary' performative utterance or whatever we like to call it. In using the imperative we may be ordering you to shut the door, but it just isn't made clear whether we are ordering you or inciting you or tempting you or one or another of many other subtly different acts which, in an unsophisticated primitive language, are very likely not discriminated. (Austin, 1956, p. 244)

The central idea of the performative analysis is to reverse Austin's account, analysing primary performatives as covert or abbreviated explicit or modalized performatives, and then to draw on the indicative forms of the latter to award them a propositional analysis. ${ }^{2}$ So, on the explicit performative analysis, (2-a) is considered to be a shortened form of (2-b), and (2-b) expresses a proposition that is true if, and only if, at the moment of speaking the speaker is ordering the addressee to shut the door.

There are two versions of the analysis, corresponding to the two types of performatives. The analysis using explicit performatives is due to Lewis (1972), who based his ideas on Ross' (1970) account of indicatives. Ross argued for the existence of a deleted phrase "I say to you that" in all simple indicatives, based on evidence that we would now mostly understand as indexicality. As Lewis noted, we cannot identify the meaning of a simple indicative with those of its explicit performative counterpart, because their truth conditions do not coincide: every explicit performative is true if it is merely uttered sincerely. However, since we do not have

\footnotetext{
${ }^{2}$ Instead of constatives and performatives, I will differentiate between declarative and imperative sentences or forms, that can be used to make statements and give instructions, respectively. I do not exclude the possibility of nondiscriminating forms, such as "You shut the door".
} 
to reckon with intuitive truth conditions of nonindicatives-since, intuitively, they do not have truth conditions-, we can safely identify them with their explicit performative counterparts and assign them the truth conditions of those explicit performatives.

The analysis using modal performatives goes back to Chomsky (1975) and Katz and Postal (1964). They motivated their analysis by reference to, amongst others, the possibilities for tags in imperatives.

a. Shut the door, (will you/*did you/*must he)!

On the basis of such evidence, Katz and Postal concluded that the underlying logical form of imperatives is "you will VP',

If imperatives are indeed 'abbreviated' indicatives, then they should have the same semantic analysis. If, furthermore, an utterance of (2-b) is semantically analysed as a proposition, which is only pragmatically interpreted as a performative due to its propositional meaning [e.g., Bach (1975), and other proponents of the indirect speech act analysis], then imperatives would semantically be analysed as propositions. Disregarding the problems with the indirect speech act analysis here, the major obstacle for this conclusion is the fact that imperatives are not naturally evaluated as true or false.

There have been at least three explicit attempts to circumvent this obstacle. Katz and Postal argued for the presence of an abstract morpheme $I$ that triggers the deletion of the auxiliary "will" and, optionally, the subject "you". This $I$ is the feature that forces its performative interpretation. Although they do not clarify the idea, presumably this forcing of the performative interpretation would account for the inappropriateness of evaluating the imperative as true or false. The account was not worked out and a decade later Katz (1977) offered an account that in fact comes closer to the parameter analysis. Another attempt was made by Davidson (1979). With his paratactic analysis of complementation, he analysed the explicit performatives as a pair of statements, as in (4-b). But a pair of statements is not true or false, and so imperatives are not true or false.

(4) a. I command that you shut the door.

b. You will shut the door. I command that.

An obvious worry with this analysis is that the speaker is still considered to have made two statements - or rather, to have made one statement and engaged in one act of 'same-saying'. But the intuition is not just that the imperative is not true or false: we do not normally consider the speaker to have made any statement, to have done anything that can be evaluated as 'true' or 'false'. So a reaction with 'YYour statement that you command something is quite true", or with "I am not going to make that indicative sentence true", are nonsensical in response to an utterance of the imperative "Shut the door".

A third attempt to account for the intuitive lack of a truth value is due to Schwager (2006). She proposes a Kratzer-style intensional semantics for imperatives, in which the imperative operator reads (roughly) "In all of the optimal 
possible worlds, given the speaker's relevant beliefs and pro-attitudes, it is the case that ...'. That is, the imperative operator is a graded modality, dependent on a contextually given ordering source (typically representing the speaker's desires, aims, goals, wishes, etc.) and a modal base restricting the alternatives to the common ground (plus certain facts the speaker is considered an expert on). As Schwager notes (pp. 71, 99, 140), a problem for this analysis is that it is truth conditional, i.e., it implies that imperatives are true or false. She suggests that this problem can be overcome by adding a set of presuppositions to the semantic analysis of the imperative operator. These presuppositions are intended to ensure that the conditions under which the imperative may felicitously be used are such that the utterance evokes a performative effect, i.e., that of issuing a command.

Presuppositions constrain the conditions under which truth values can be assigned to an expression, or those in which it can be felicitously uttered, but it is not clear how presuppositions could account for the overall inappropriateness of assigning a truth value when it does have a truth value, or when it can be felicitously uttered. Perhaps the presuppositions of imperatives under Schwager's analysis successfully constrain the use of the imperative operator to precisely those circumstances in which the speaker could also felicitously issue a command and, moreover, maybe the use of the imperative operator under such circumstances does evoke a performative effect. But still the expression could appropriately be called 'true' or 'false', unlike imperatives.

About the remarks of a completely reliable authority we might say, albeit redundantly, "true as always" in response to her modal indicatives, but not in response to her imperatives. Furthermore, a speaker could qualify a modal indicative epistemically, unlike imperatives: by coordinations with "you don't know it yet, but ...'” or "'you will be shocked to find out, but ...'” and by qualifications such as "'there's no denying it", 'you will find out soon enough', and "'as any student of organic chemistry knows". These qualifications are not blocked by the presuppositions Schwager mentions and, more generally, I do not see how any set of presuppositions could block the qualification of a truth value bearing expression as (non)veridical.

As has been noted by several authors, in some cases indicative sentences with modal auxiliaries are also not appropriately evaluated as true or false: to "You must clean the bathroom, right now!' the response "True as always", would not make any sense. ${ }^{3}$ Rather than viewing this as an argument to qualify both those modal indicatives and imperatives as (covertly) truth-evaluable, I think it indicates that those modal indicatives (in context) cannot be treated as expressing propositions. In this sense the modal indicatives have the same semantic analysis as imperatives: they convey instructions, not (modal) propositions. The imperative semantic analysis need not be strictly correlated with sentences that have an imperative verbal or grammatical mood: what in some languages is expressed with verbal mood is in other languages conveyed by modal auxiliaries. What makes imperatives interesting

\footnotetext{
3 See Ninan (2005) on the meaning of deontic 'must'. For a further example, consider also Veltman's (1996) objection to assigning a truth value to "It might be raining".
} 
is the fact that they grammatically indicate the impossibility of having a propositional interpretation.

\section{The parametric approach}

The parametric analysis is perhaps the most common view among semanticists. Its originators are Stenius (1967), Searle (1969) and Hare (1949). The analysis is supported by anyone who argues that sentences have, in their grammar, a parametric feature determining the mood or illocutionary force of the clause (e.g. Han 1998), and by anyone who argues that a proposition is only a statement when it is added to a 'belief set' or 'commitment slate' and, perhaps, that we can add the proposition to a 'question set' or a 'to do list' as well, thereby determining its conversational function as question or instruction. ${ }^{4}$

The basic idea of this approach can be illustrated as follows.
a. It is the case [that the door is shut].
b. Let it be the case [that the door is shut]!
c. Is it the case [that the door is shut]?

The proposition is a 'that' clause and has a propositional content, but it needs to be in the slot of a mood expression to form a meaningful utterance. Without the mood, the propositional content is like a 'picture', a representation of a state of affairs, a reference to a possible event, or some such thing. Semantics is the practice of assigning such contents to the 'that' clauses, pragmatics deals with the formulation of general rules for the appropriate use of the mood expression in conversation, constituting the meaning of that expression.

As a piece of historical irony, the view has been inspired by Frege and Wittgenstein, who both opposed it explicitly. In The Thought, Frege suggested that interrogatives have the same senses as propositions. However, he continued:

We should not wish to deny sense to a command, but this sense is not such that the question of truth can arise for it. Therefore I shall not call the sense of a command a thought. Sentences expressing wishes or requests are ruled out in the same way. Only those sentences in which we communicate or assert something come into the question. (Frege 1918, p. 62)

\footnotetext{
${ }^{4}$ The view of Hausser (1978) and Portner (2005) is different, but related. According to this view, imperatives express properties. Hence, they are semantically distinct from declaratives, which express propositions. However, as Portner clarifies, what makes the property-expressing utterance specifically imperative is the fact that its conversational use is governed by a rule that this property is to be added to the addressee's 'to do list'. Accordingly, although on this account the conversational function selects for some semantic type, the expressions of that type does not intrinsically have the conversational function but require the context of conversational rules to give them that function. A similar point can be made with respect to the interrogative semantics of Groenendijk and Stokhof (1984): interrogatives have a semantics in terms of partitions, but what makes the partition-characterising utterance specifically interrogative is the fact that the partition determines what counts as an 'answer' in the conversation. The update semantics of Groenendijk (1999) makes this pragmatic element part of the meaning, by analysing interrogatives as performatives partitioning the state space.
} 
Of course it is somewhat strange to deny that commands communicate something. But the point is nonetheless clear: the question of truth is constitutive of the concept of a thought. Since commands are not called true or false, they do not express thoughts-despite the fact that they do have a sense.

One comment by Wittgenstein (1953) inspired Stenius to formulate his account in terms of 'sentence radicals'. However, this comment by Wittgenstein was in fact intended as a footnote to a criticism of the parametric view on utterance meaning, suggested by Frege's (1879) use of the 'judgement stroke'. Here is the main argument.

Frege's idea that every assertion contains an assumption, which is the thing that is asserted, really rests on the possibility found in our language of writing every statement in the form: "It is asserted that such-and-such is the case." But "that such-and-such is the case"' is not a sentence in our language-so far it is not a move in the language-game. And if I write, not "It is asserted that ...", but "It is asserted: such-and-such is the case", the words "It is asserted" simply become superfluous. (Wittgenstein, 1953, 22)

Wittgenstein thus argued against the suggestion that the judgement stroke reveals a two-layered structure in the sentence, distinguishing the "assumption" from the judgement that the assumption is true. He then uses this argument to reject the suggestion that the assumption is present in all sentences. In the aforementioned footnote, Wittgenstein attempts to clarify the intuition behind the two-layer approach, by referring to pictures we might use to communicate various messages as "sentence radicals", drawing on the analogy with chemistry. The sentence radical account, as I will understand it here, is that the proposition as such is incomplete and must be connected with a mood or sentence type to be meaningful utterance-just as a hydrogen atom and a chloride atom must be connected to be a stable molecule. In this sense the sentence radical theory treats the imperative as a parametric compound.

The main problem of the parametric analysis is that it conflicts with the idea that the primitives in a theory of meaning are-besides what we refer to (the type $e$ ) - what we make judgements about (in a Fregean perspective) or what we use in language games (from a Wittgensteinian point of view). The meanings of the sentential constituents are inherited from these primitives by functional abstraction. We can attempt to assign primitive meanings to other expressions to avoid this problem, but those attempts have not been successful to date.

We could consider 'that' clauses, as in the examples before, or gerunds, as some have proposed Beardsley (1944) and Hare (1949), but neither will work, for two reasons (at least). ${ }^{5}$ First, in both cases a similar plurality appears at the supposed 'sentence radical level'. Next to 'that' clauses there are 'to' clauses, or infinitives, and next to 'subject-gerunds' there are bare gerunds.

\footnotetext{
5 In addition, it has been widely accepted that 'wh' clauses have a semantics of their own. A systematic argument for this thesis is presented in Groenendijk and Stokhof (1997). Still, the proposed semantic theories for 'wh' clauses fall within the scope of intensional semantics, involving basic semantic types only for truth values, entities and indices (possible worlds). Imperatives would seem to require a more radically different semantic formalism, supposing that they are not truth evaluable.
} 
(6) a. Harry remembered that Joe was hosting a party that evening.

b. Harry remembered to bring a gift for Joe.

(7) a. I enjoyed my playing the piano.

(Lakoff 1972)

b. I enjoyed playing the piano.

Verbs that can take either a 'that' clause or an infinitive are not very common-'know' and 'hope' are other examples-but the contrast between their respective contributions is nonetheless clear. The same goes for the gerunds: in the (a) case the speaker enjoyed the playing as an observer and in the (b) case she enjoyed it as an agent. So, rather than finding a unity at the subsentential level, we encounter a further diversity.

Standardly, infinitive complements are analysed as propositions. The difficulty is to say which propositions they are. This issue could be resolved by proposing a correspondence between infinitives and 'that' clauses such that the infinitives can be substituted by the corresponding 'that' clauses. It seems unlikely that this can be done, because apparently no 'remember that' sentence expresses what a 'remember to' sentence expresses. Alternatively, the propositional analysis remains speculative; e.g. in generative linguistics it involves a silent subject PRO and a silent modality Stowell (1982) for which only abstract semantic characterisations have been given.

The second problem is that the entailment relation can no longer be regarded as a relation between sentences. Entailment is on this view not truth preservation, but some abstract relation between complementizer clauses, infinitives or gerunds. Hare (1949) gives the following example.

Use of axe or saw by you shortly

No use of axe by you shortly

Ergo: Use of saw by you shortly

It is not clear what could possibly motivate the claim that this is a valid inference, unless we grant a propositional or instructional interpretation to the gerunds, as if it were just a silly way of making statements or giving orders. The entailment relation between gerunds or other clauses will result in pragmatic relations between sentences-perhaps exactly the relation of truth preservation for declarative sentences. But in order to study entailment as such, and to determine which of these inferences' is valid, data or intuitions about sentences are of no (direct) relevance.

The fact that truth values are the primitives in semantics is based on the awareness that the data or intuitions we base our semantic analysis on are ultimately derived from intuitions regarding what is true, valid, equivalent, meaningless, contradictory, or tautological. And these intuitions regard the use of sentences in linguistic practices: conversation, inference, debate, and so on. If we can accept that such intuitions may be pluriform, including intuitions about what is complied with, required, a conflict in commitments, contrary to duty, and so on, then that is all we need to justify a pluriformity of semantic primitives of the sort I am proposing here. 


\section{The operator approach}

Proponents of the operator approach are Hofstadter and McKinsey (1939), McGinn (1977) and, perhaps, Belnap (1990). ${ }^{6}$ I know of no more recent proponent of this approach. Superficially, it is a slight variant of the parametric approach. To illustrate:

(8) a. It is the case that [the door is shut].

b. Make it the case that [the door is shut]!

c. Is it the case that [the door is shut]?

The part between square brackets is itself also a sentence of the language, and it has a truth value when used in an appropriate context. The declarative operator is not needed, or it is a dummy: it would not contribute to the meaning of the sentence (see McGinn 1977, p. 307), but the other two operators do. What I take to be characteristic for the operator approach is Belnap's 1990 thesis that "declaratives are not enough': the imperative (and other non-declaratives) not only differs in use from declaratives, but also in logical form and meaning. The operator approach is therefore closer to the view I am proposing here, insofar as it recognises specifically imperative semantic values. The difference consists in the idea that the imperative mood can be represented as an operator that leaves the truth conditional analysis of indicatives and their component expressions unaffected. That is, rather than viewing natural language expressions as contributing indiscriminately to simple and complex sentences of different moods, the operator approach offers a layered perspective on non-declarative sentence meaning, separating declaratives from nondeclarative operators scoping over them.

Hofstadter and McKinsey limit their discussion to impersonal imperatives, which they call 'fiats'. A fiat is constructed from a declarative sentence by means of the fiat operator "Let it be the case that", or simply "!?'. They introduce a variety of special imperative connectives, such as imperative negation, disjunction and quantification, but they do so in such a way that they can prove that all those connectives are logically redundant.

This theorem amounts to saying that all imperative-connectives can always be eliminated from a [declarative] sentence, and that all imperative-connectives except for one [fiat operator] "!'” symbol can always be eliminated from an imperative ...(Hofstadter and McKinsey 1939, p. 452)

Hamblin (1987, p. 102) ridiculed this view by remarking that according to them "all that is necessary to construct a logic of fiats is to get a good book on the logic of indicatives and inscribe an exclamation mark on its title-page.'

McGinn's aim is to present a compositional theory of meaning in which (i) the semantic contribution of expressions to sentence meaning is independent of the mood of the sentence, although (ii) sentences in different moods have different semantic

\footnotetext{
${ }_{6}$ McGinn also presents a direct speech analysis (in effect a slight variant of the operator analysis) on which the imperative reads "Make this the case: the door is shut".
} 
values. So, words must contribute uniformly to the meanings of both declarative and imperative sentences in which they figure (i), but imperatives do not have truth values (ii). The solution to this problem that McGinn proposes, is to transform the parametric approach into a compositional semantic one, by introducing an imperative operator "Make it the case that' scoping over a declarative sentence.

The ambition is, clearly, that the meaning of all expressions other than this imperative operator (and the other mood operators) be characterised in strictly truth conditional terms. ${ }^{7}$ If the imperative operator could (nontrivially) embed under expressions that also figure in declarative sentences, then McGinn's project would fail. Consequently, all ordinary imperatives will have to be construed as mere notational variants of "Make it the case that" imperatives (henceforth M-imperatives), and such that the former can be systematically correlated with their corresponding M-imperatives. According to McGinn, imperatives are not 'true' or 'false', but 'fulfilled' or not. The following schema allows us to systematically relate the fulfilment conditions of imperatives to the truth conditions of declaratives (relative to a time of evaluation).

\section{F-T Fulfilled( $\ulcorner$ Make it the case that $A\urcorner$ at $t)$}

$\equiv$ It is made the case that $\ulcorner A\urcorner$ is true at $t$.

I have two general objections to this proposal. The first is that the concept of 'fulfilment' is insufficient to characterise imperatives as such. Not only imperatives can be fulfilled (or not), but the same goes for promises, wishes, expectations, guesses, and even future tense statements. The schema at most enables us to differentiate imperatives amongst each other, but not to characterise them as imperatives. Perhaps part of this concern is accommodated by the reference to "making it the case that ... is true" in the right hand clause, but this is at the expense of introducing agency (truth making as opposed to mere truth) as a meta-linguistic concept. Moreover, arguably mere truth making is not enough for fulfilling an imperative: the truth making should be intentional, deliberate, or "whole-hearted" in Hamblin's 1987 terminology.

The second objection is that the proposal is entirely promissory. Its major premise is that we can systematically analyse all imperatives that do not begin with "Make it the case that' as equivalent in meaning to an imperative that does have this initial phrase. But this premise has not been justified: no concrete 'translation' from imperatives to the equivalent $\mathrm{M}$-imperatives has even been suggested by McGinn or any other proponent of this approach.

Presumably the assumption is that we can analyse complex imperatives-i.e., those involving connectives, quantifiers and such — as equivalent to M-imperatives with complex propositional arguments. Although appealing at first sight, I believe that on closer inspection this assumption turns out to be problematic: various complex imperatives do not afford a reformulation as an M-imperative. I do not yet see a problem with the systematic reformulation of simple imperatives as

\footnotetext{
7 That McGinn adopts a Davidsonian extensional approach rather than a Montagovian intensional one is insubstantial to this issue.
} 
M-imperatives, although it still has to be shown to be possible for them-and pending a proper response to the first objection. ${ }^{8}$ If I am correct about this, then imperatives are themselves the arguments of semantic operators, such as negation, disjunction, quantification and modality.

Below, I will consider five kinds of complex imperatives. First, I will briefly consider conditional and negative imperatives. Disjunctive imperatives will lead me to discuss the Ross paradox. Then I will consider more peculiar complex imperatives: those with a quantified or third person subject, and counterfactual imperatives. I argue that the F-T schema cannot adequately handle those cases.

\subsection{Conditional imperatives}

First, consider conditional imperatives. We might want to equate them with M-imperatives with indicative conditional arguments, as in (9-a), but the rendering in (9-b) seems more appropriate.

(9) If it gets cold, shut the window.

a. Make it the case that, if it gets cold, the window is shut.

b. If it gets cold, make it the case that the window is shut.

Depending on one's analysis of conditionals, the former might be taken to imply that the imperative is fulfilled as long as it does not get cold. It is more natural, I believe, to say that there is no obligation induced by the conditional imperative as long as it does not get cold: the imperative is neither fulfilled nor unfulfilled in that case. For this reason, the second rendering seems to me more plausible.

\subsection{Negative imperatives}

A second case concerns negative imperatives. Again, two analyses seem to be available.

(10) Don't shut the window.

a. Make it the case that the window is not shut.

b. Don't make it the case that the window is shut.

The first of these is an M-imperative with a negated propositional argument, the second is the negation of an M-imperative (whatever that may be). An objection to the former 'translation' is that this sentence would also require that one open the window in case it is shut. The negative imperative just seems to demand some form of inaction, a certain kind of refraining, rather than any action of ensuring something.

An alternative M-imperative might be opted: how about "Make it the case that you do not shut the window"? But in that case the imperative orders the ensuring of one's refraining, rather than simply that it orders one's refraining. It is not very clear what ensuring that one does (not do) something means precisely. Perhaps it means that one is in complete autonomous control over one's actions, or that one is acting

\footnotetext{
${ }^{8}$ How about simple imperatives such as "Act erratically" or "Make nothing the case",?
} 
without any social, moral, and environmental restraints. In any case, it seems clear that we need not decide this issue in order to determine whether or not I refrained from shutting the window. For instance, I could push against a pin that prevents the window from falling shut, where the amount of force I exert on the pin neither ensures that the pin is released nor that the pin stays in place. In that case, if the window does not shut, did I not refrain from shutting it without ensuring that I did so? Perhaps one rejects the physical non-determinism that is suggested by the story, but that should be quite independent of the semantics of imperatives. The restriction to M-imperatives implies that all imperatives be interpreted as (equivalent to) demands for ensuring something, whereas the above remarks indicate they need not.

\subsection{Disjunctive imperatives}

The problem with disjunctive imperatives is similar to that with conditional imperatives: the M-imperative with a disjunctive argument suggests that all that the imperative requires is that the disjunction be true.

(11) Shut the window or shut the door.

a. Make it the case that the window is shut or the door is shut.

b. Make it the case that the window is shut or make it the case that the door is shut.

A problem for that view is the familiar idea that disjunctive imperatives grant the addressee a free choice. The semantic substance of that idea is that, if correct, the disjunctive imperative would not be consistent with the prohibition (negation) of either one of the disjuncts. In an attempt to deny this, Rescher and Robison present the following example (also quoted by Aloni 2005).

(12) Teacher: 'John, stop that foolishness or leave the room!'

John gets up and starts to leave.

Teacher: 'Don't you dare leave this room!'

The authors claim that the teacher is merely "explaining"' her earlier command, not "abrogating", it. I believe they are mistaken. The teacher may have meant many things with her first utterance, but by making the utterance she offered John a choice. At best one might analyse the first command as flouting the Gricean maxim of Quality. That is, the command could be understood as offering something so unrealistic (i.e., allowing the student to leave) that it cannot be taken seriously, thus giving additional urgency to the (implicated) instigation to stop the foolishness. But then we acknowledge that the literal meaning of the teacher's instruction is that a choice is being offered. ${ }^{9}$

\footnotetext{
9 Possibly, the M-imperative with a disjunctive propositional argument is still interpreted as granting a free choice. If so, the problem of the operator approach in this case is not so much the demand that each imperative is equivalent to some M-imperative, but rather that the F-T schema, combined with a standard truth conditional semantics for declaratives, gives us an adequate semantic analysis of the meaning of M-imperatives with disjunctive arguments.
} 
The idea that a disjunctive declarative is consistent with the negation of one of its disjuncts is supported by considering a discourse of, say, a detective summing up the gathered evidence as follows.

(13) Well, the thief came in via the window or he was hiding in the cellar. And he did not come in through the window.

No such discourse is possible for imperatives, because imperatives cannot be used to merely recapitulate the instructions or commitments one has gathered thus far.

In order to rescue the operator analysis, one may insist that the M-imperative translation is semantically correct, with a classical interpretation of disjunction, but that the implicature of free choice cannot be cancelled. The literal, semantic meaning of disjunctive imperatives would then become entirely abstract and impossible to obtain. The alternative is to analyse the semantic value of 'or' as functionally dependent on the clause type, embedding operator, or conversational context [Geurts (2005) offers such a proposal]. Whether a particular disjunctive sentence is presenting the alternatives as genuine (free choice) or not, or is ambiguous, is then a matter dependent on the construction in which it appears. In particular, this approach will allow us to consider imperatives as a context in which 'or' always gives rise to a free choice semantic analysis, whereas in declaratives it need not. The framework in section 6 develops this idea. ${ }^{10}$

\subsection{The imperative subject}

It has been widely acknowledged in the linguistics literature that imperative sentences in various languages can have a subject. Here are some in English.

(14) a. You go home now.

b. You two take this end and your spouses take the other end.

c. Somebody get this table out of the way.

d. Whoever bought this television bring it back.

e. The oldest of the girls sing a song for daddy.

f. Nobody move a muscle.

It has been argued convincingly that these subjects are not vocatives. Schmerling (1975) has the following observations: (i) vocatives can be supplemented with the word 'there', as in (15-a), (ii) vocatives can co-occur with imperative subjects, as in (15-a), and (iii) only imperative subjects allow for quantifier floating, as in (15-b).
a. You there, you sit still.
b. You both (*there) pay attention.

\footnotetext{
10 The issue gets more complex when we consider performative disjunctive permission sentences, such as the ones Kamp $(1973,1979)$ discusses. I believe for them as well the free choice interpretation is uncancellable, given their contextually determined function as performatives. Kamp's counterexample (Kamp 1979, p. 271) is unconvincing, because "but" clauses are not a good test of cancellation. Those clauses can also be used to 'cancel' features that are undeniably part of the semantic meaning of an expression. But motivating that claim would take us too far afield here.
} 
Beukema and Coopmans (1989) add the observation that an imperative quantified subject can bind a pronoun, unlike vocatives.
a. ${ }^{*}$ Somebody $_{i}$, take off his h $_{i}$ coat.
b. Somebody take off his $_{i}$ coat.

We can furthermore add the semantic argument that 'nobody' can be an imperative subject although it cannot sensibly be used as a vocative.

It will be clear that the imperative subject poses a problem for the operator approach. We cannot translate, say (14-d) into (17).

(17) Make it the case that whoever bought this television brings it back.

Someone who uses this latter sentence must be addressing some particular person or group who are instructed. By contrast, (14-d) can only be uttered by someone who does not know who the addressee of the instruction is. Similarly, (14-c) is uttered by someone who does not care who does the actual moving. Its presumable translation (18) is always addressed to someone, as an instruction to delegate the task of moving the table.

(18) Make it the case that somebody gets this table out of the way.

I think the solution to this problem is evident: the imperative subject must scope over the imperative operator:

(19) Somebody make it the case that this table is out of the way.

As far as these examples go, the subject of an imperative would seem only to constrain the intended addressee as part of the audience. But typologists also point to the existence of first and third person imperatives, that make the instruction addressed to someone outside of the audience of the utterance act. Typological data on third person imperatives (e.g., van der Auwera et al. 2003) are difficult to evaluate and often questioned, as it is not quite clear how there could be third person imperatives: if the point of an imperative is to instruct someone, then how can the subject, the person instructed, not be in the audience to the utterance? However, it is precisely semantics that should explain the peculiarities of the interpretation of third person imperatives by reference to the combination of third person and the imperative semantics. In the following I make use of examples from Dutch. This language does not have a syntactically third person imperative construction, but it does have a construction that should be identified as having the interpretation of a third person imperative. Investigating this construction may help us to get somewhat more clear on the idea of third person imperatives itself.

Whereas French, for instance, has a special form for first person plural imperatives, e.g. 'CChantons!', English has the verb 'let' to express such proposals to the collective of which the speaker is a part, e.g., 'Let's sing!'. The verb 'let' can also be used as the main verb of an ordinary second person imperative. The difference can be marked with tags. 
(20) a. Let's go to the beach, shall we?

b. Let us go, will you please?

As such, the distinction may be thought to be pragmatic: the intuitive difference in meaning resides merely in the pragmatic issue whether the hearer is part of the group denoted by 'we' or not.

Dutch has a verb 'laten' quite similar to English 'let': it also has the two uses, but unlike English the first person imperative construction can be singled out by a nominative case on the pronoun following 'laten'.

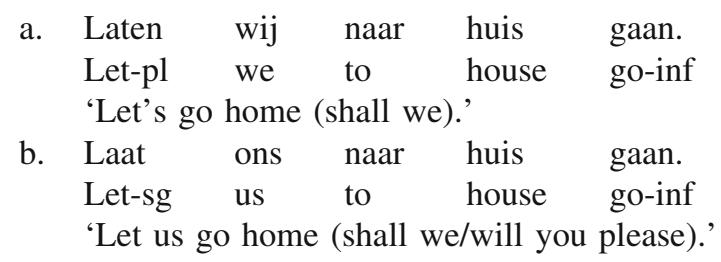

In the first person imperative construction the verb has to agree with the nominative pronoun, unlike in the ordinary (second person) imperative. The construction with accusative subject can also be used as a first person imperative, albeit archaically. But the construction with a nominative pronoun cannot be used as a second person imperative.

On top of this, the 'laten' construction also distinguishes nominative and accusative third person pronouns. As a consequence, we can grammatically single out the third person imperative in Dutch.

a. Laten zij eerst maar eens hun excuses a
Let-pl they first prt prt their apologies offer-inf
'Let'em first offer their apologies.'
b. Laat hen eerst maar eens hun excuses
Let-sg them first prt prt their apologies offer-inf

'First let/make them offer their apologies.'

The second of these is again an ordinary imperative, with imperative verb 'laten' ('let', 'allow', 'make') and addressed at the hearer. The former, on the other hand, has a meaning that is not easily expressed unambiguously in English. It concerns the actions to be executed by some group disjoint from the audience of the utterance. Importantly, the hearer need have no connection with the group referred to with the third person pronoun. For instance, the speaker might be discussing the behaviour of her colleagues with a friend who does not know any of these colleagues. In that case the meaning of (22-a) can be described as an instruction for an absent addressee. If the group of persons referred to would be present, the speaker would address them directly, with a simple second person imperative.

There are two different ways of accounting for the 'laten + 3rd.nom' construction of (22-a). One possible account is that these sentences have a specific conversational function, call it absentive, which is tied to the grammatical 
construction as a whole. We have then identified a correlation between a grammatical form and a conversational function and treat this as similar, but not compositionally related to the imperative. ${ }^{11}$ The other possible account, which I prefer, is to explain the conversational function compositionally, by analysing it as the result of embedding an imperative under a context shifting operation, expressed by 'laten' and the nominative pronoun. That is, the speaker intends to give advice or make a request to someone, but this person is not present and so cannot be addressed. This means that the speaker has to present the situation $a s$ if the person in question is present in order for the utterance to be meaningful as advice or request. This shift in the context is marked by the 'laten +3 rd.nom' phrase heading the sentence. The fact that the speaker is shifting the context explains the difference between absentives and ordinary requests: by a request we mean something the addressee can fulfil by performing some action; but here the addressee is not really present, so the normal reaction to it is precluded. And this preclusion is what explains the utterance being understood as an absentive.

Intuitively, we can think of third person imperatives as:

3rd (Make it the case that you offer your apologies).

The operator 3rd is similar to a modal operator in shifting the a contextual parameter away from its contextually determined default value. In this case, it shifts the addressee-parameter away from the default, the audience of the utterance act, to some absent party-just as a tense operator shifts the time of reference away from the present to some 'absent' time.

In what follows I will not develop a formal semantic account along these lines. ${ }^{12}$ I will offer a formal semantic account of counterfactual imperatives in the next sections, which involves embedded imperatives. I believe that a semantics of third person imperatives can be developed in an analogous way.

Interestingly, Schmerling (1982) proposed an analysis of the imperative subject that is precisely the opposite of what I am proposing here. According to her, the basic meaning of imperative and hortative forms (i.e., 'let'/'laten' constructions) is the expression of an attempt to bring about a change in the world. What we normally call 'imperatives' are in fact the result of restricting this basic meaning to those cases where the subject is interpreted as an addressee, who can assist the speaker in bringing about the desired change. In case the subject is not interpreted as the addressee, the sentence has an optative interpretation, i.e., as the expression of a wish or a prayer. In other words, the imperative is analysed as a presentive or addressive conversational function of a more basic semantic notion. ${ }^{13}$

If this would be possible, we might be able give an equally integrated semantic analysis of imperatives and hortatives by means of a single operator "Let it be the

\footnotetext{
${ }^{11}$ Of course there is no reason to oppose naming this construction "absentive". What I do oppose to is the idea that we need not bother with a compositional semantics of the construction because it would not be an imperative but an absentive, as a means of rescuing the operator approach to imperatives.

12 A first attempt can be found in Mastop (2005).

${ }^{13}$ In so doing, Schmerling also intends to include a variety of root infinitives into the same clause type as imperatives. See also Bolinger (1977) for a related view.
} 
case that ...', combined with a pragmatic analysis of addressing such sentences. In this way we might avoid the need for an addressee-shifting operator scoping over simple imperatives, as I am proposing. To consider this option, we should take a closer look at 'impersonal' 'laten' sentences, such as (24) and (25).

$\begin{array}{llll}\text { Laat er } & \text { gedanst } & \text { worden. } \\ \text { Let there } & \text { dance-pp } & \text { become-inf }\end{array}$

'Let there be dancing.'

Laat het alsjeblieft gaan regenen.
Let it please go-inf rain-inf
'Let it please start raining.'

Hofstadter and McKinsey (1939) and Kenny (1963) call these kinds of sentences 'fiats', analysing them as imperatives with no indication of an addressee-by contrast to imperatives that are 'directives'. This formulation is not clear. Some imperatives and 'let' sentences do not explicitly specify the addressee, but that does not mean they are not directives. For instance, (24) could be used by someone orchestrating a party as a demand that at least some of the attendants dance, without specifying which of them. If, on the other hand, the idea is that fiats are like directives but without any addressive function, then that makes no sense. Even a mystical use of (25) as a means to make it start raining would be an act presupposing an animistic conception of nature as something that can obey one's command. Such cases do not undermine an analysis of 'let' sentences as (shifted) directives any more than the use of interrogatives without an addressee (e.g., "Why did this have to happen to me, of all people?') undermines the semantic analysis of interrogatives in terms of the set of its possible answers.

Apart from this, the impersonal 'let' construction is also used to express wishes and in prayer, much like the archaic subjunctive construction in (26).

$$
\begin{array}{llll}
\text { Moge het alsjeblieft } & \text { gaan regenen. } \\
\text { May-subj it please } & \text { go-inf } & \text { rain-inf } \\
\text { 'May it please start raining.' } & &
\end{array}
$$

Although this is indeed different from the directive and shifted-directive uses of imperatives and 'let' sentences, it would not suffice to take this use as basic and explain directives as 'addressed wishes'. A wish does not turn into a directive by being addressed to someone. And (26) cannot be used to issue an instruction, although one can certainly address it to someone (wishing it for someone, expressing one's wish to someone).

\subsection{Counterfactual imperatives}

The second argument against the operator analysis of imperatives is the possibility of irrealis in imperatives in Dutch. There are two constructions we may consider. 


Was toch lekker thuisgebleven.
Was prt prt at.home.stay-pp
'You should just have stayed at home.'

Gaf hen dan maar geen bekeuring.
'Gave-sg them prt prt no fine'
'You had better not give them a fine.'

The first of these is a commonly used construction, by means of which the speaker reproaches the addressee, telling him what he should have done. The second is a less frequently used construction, about which different subjects appear to have rather different intuitions. One use of that construction that is widely recognised is in narratives about generic scenarios in the distant past: 'in those days, this was the wise thing to do'. Yet, it has been called into question by some syntacticians and it is not recognised by Dutch grammar overviews (cf. ANS 1997). For these reasons, I will focus exclusively on the former construction, which is undisputed. ${ }^{14}$

Bennis (2006) claims that sentences like (27) are "optative constructions"' rather than perfective imperatives. Wolf (2003) similarly argues that they are not really imperative. The reason he gives is that these past participle sentences do not have present tense equivalents, because there the irrealis reading is excluded.

*Heb dat dan toch ook eerder gedaan!
Have that prt prt prt earlier do-pp
'Have done that earlier!'

Contrary to these claims, I will argue that we had best consider (27) as a genuine counterfactual imperative. ${ }^{15}$

The first step in this argument is to note that there is an important role for the particles in this construction. The particles 'toch' and 'dan' do not combine with a subject, unlike the particle 'maar'.
a. Was
(*Jan) toch
lekker
thuisgebleven.
b. Was (Jan) maar lekker thuisgebleven.

The difference in meaning is also clear: (30-b) is a real optative and glosses 'If only Jan had stayed at home'. Such an 'if only' gloss is not appropriate for the construction with 'toch' and 'dan'. This contrast shows that the particle 'toch' can constrain the sentence to a reproach meaning, blocking the optative interpretation.

The second step is to consider the meaning of the Dutch past participle construction. In combination with a present tense auxiliary, the past participle mostly leads to a resultative interpretation, but in the context of a past reference time it can also lead to a perfective reading. With an utterance of (31) the speaker indicates that

\footnotetext{
14 Though see Wolf (2003) for a compelling analysis of the simple past imperatives as genuine past tense imperatives, both for Dutch and Frysian.

15 One unexplained difference between simple imperatives and the counterfactual construction remains: the latter does not allow for any explicit subject.
} 
the dressing took place after having gotten up and that the activity of dressing herself was completed. It does not mean that the result state continues into the present and hence that speaker is dressed at the moment of speaking.

(31) Nadat ik was opgestaan, heb ik mijzelf aangekleed. After I was up.get-pp, have I myself on.dress-pp

'After I had gotten up, I dressed myself.'

The difference between the past participle construction in past and present tense contexts is important here, because it explains the oddity of (29): if the reference time is present, the past participle imperative obtains an unintelligible resultative interpretation, namely that some action be completed at speech time; but if the reference time is past the expression does not get a resultative interpretation, but indicates that the activity occurs after the reference time and (when relevant) that it be completed. It should be noted that the unintelligibility is also due to the occurrence of the aforementioned particles, which exclude a wish-interpretation, as in (32).

$$
\begin{aligned}
& \text { Heb (*dan toch ook) alsjeblieft niet nog een vaas gebroken. } \\
& \text { Have (prt prt prt) please not again a vase break-pp } \\
& \text { 'Please don't have broken another vase.' }
\end{aligned}
$$

The past participle construction in counterfactual imperatives places the event (i.e., the action that should have been undertaken) in the past, in the same manner as it does in (31). To strengthen this point, we can consider the infinitivus pro participio (IPP) construction, which is used to focus on the inception of some activity or process, and does not imply its completion. It is used in similar contexts as the past participle, as (33) shows. There are, accordingly, also counterfactual imperatives with this construction, such as in (34).

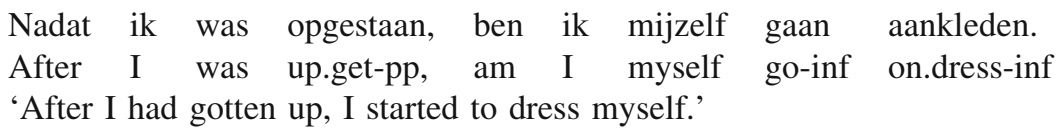

Was jezelf dan ook gaan aankleden.
Was yourself prt prt prt go-inf
'You should just have started to dress yourself.'

It is not entirely clear why the counterfactual imperative requires the past participle or IPP construction, instead of the simple tense (assuming we exclude the simple past imperatives Wolf mentions). To explain this requires an in depth study of Dutch grammatical aspect, which is beyond the scope of this paper. But the important point is that the past participle and IPP constructions are used to indicate an event time prior to the speech time, after some reference time, and without a resultative meaning.

The main remaining difference between (27) and (31), or between (34) and (33), is the fact that the imperatives have a past tense verb. The third and final step of the 
argument concerns this fact. A difference between English and Dutch is that in Dutch mere past tense can be given an irrealis interpretation. That is, in (35) we can see that a simple past is used in the consequent of a counterfactual conditional. The past tense is enough to express the counterfactuality of the context, where in English one needs a modal 'would' to do so.

Als Jan vandaag niet ziek was, ging hij morgen op vakantie. If Jan yesterday not ill was, went he tomorrow on holiday 'If Jan weren't ill today, he would go on holiday tomorrow.'

Combining these three observations, we get the following analysis of the counterfactual imperative construction in Dutch: it is the past participle or IPP construction that indicates that the activity occurs after some contextually determined time in the past; and it is the past tense that is required to mark the non-factuality of the imperative. It is because we embed the imperative in this counterfactual context that it obtains a reproach interpretation: it cannot be a real advice, because at the time of speaking a different decision has already been made and followed through. The particles 'toch' and 'dan ook' enable us to grammatically single out the reproach use. We have seen that this particular construction (with the particles) does not allow for a non-addressing use. It is only possible to use it to reproach the addressee for his or her actions, indicating which action should have been undertaken instead. Like ordinary imperatives, this construction cannot be used with epistemic qualifications:
a. \#Zoals elke scheikundestudent weet, had dan ook een erlenmeyer gebruikt!
As any chemistry student knows, you should have used an Erlen- meyer flask!
b. \#Je weet het nog niet, maar was toch naar huis gegaan.
You don't know it yet, but you should have gone home.
c. \#Het valt niet te ontkennen: had dan ook de truffelsaus gekozen.
There's no denying it: you should have chosen the truffle sauce.

In view of this, I believe the analysis of the construction as a complex, counterfactual imperative is the most natural one. We can think of the construction as embedding an imperative, concerning a past event time, under an irrealis mood:

(37) Irrealis(Made it the case that you went home)

Like before, we see that the operator-argument analysis of the imperative faces a problem. It cannot relegate all semantics to the argument, i.e., the proposition, because the operator itself must embed under an irrealis mood.

Schwager (2006, pp. 113-115) reserves the qualification 'imperative' for the grammatical type of sentences that are typically used to give actual instructions. For the construction discussed above she coins the term 'reproachative'. There is of course no objection to such a naming convention, but it does not justify the 
disregard for the counterfactual construction in an analysis of the grammar and meaning of imperatives, as Bennis seems to suggest. Regardless of the naming convention, as Schwager is also keen to point out, the reproachatives are most aptly viewed as both syntactically and semantically related to (ordinary) imperatives.

This concludes the discussion of the operator approach. To recapitulate, the operator approach concedes that imperatives differ semantically from declaratives, but they propose to trivialise the semantic contribution of mood by claiming that M-imperatives can express everything that imperatives can express. I have argued that this is not true: various complex imperatives do not afford a translation into the M-imperative format. Proponents of the operator approach have mostly neglected these complex imperatives. By contrast, it seems to be much more plausible that we analyse complex imperatives as simple imperatives embedded under semantic connectives and operators: negation, disjunction, quantification and modality. This suggests that there can be such a thing as a 'logic of imperatives'. After a brief discussion of that long-standing philosophical issue, the final section is devoted to a formal semantic analysis of imperatives, focussing on counterfactual imperatives.

\section{A logic of imperatives?}

The issue whether there is, or can be, such a thing as a 'logic of imperatives' goes back to the 1930s. Against the proposals for a logic of imperatives by Mally (1926), Jorgensen (1938) and others, legal positivists such as Ross (1941) argued that imperatives cannot have a logic because the concepts of validity, premise, argument and so on do not apply to imperatives. Moreover, norm conflicts are not logical inconsistencies; therefore the existence of one norm does not entail the (non)existence of another norm.

This criticism assumes that logic has to do with reasoning and inference alone. An alternative view on logic is that it is a field of research concerning a variety of related concepts including entailment, validity, consistency, contradiction, and so forth. Some of those concepts do, intuitively, apply to imperatives and others do not. Two instructions are commonly said to be contradicting if compliance with one precludes compliance with the other. Also, a permission contradicts an instruction if compliance with the latter precludes making use of the former. These are simply the common sense facts about our logical concepts and they imply that "logic has a wider reach than truth', (von Wright 1957, 1996).

In other cases we may decide to extend our logical concepts beyond their normal application, if that leads to fruitful theoretical analysis of linguistic meaning. For instance, we may speak of the valid inference of one question from another question, if that enables us to express in a perspicuous way the meaning-relations between questions and their answers Groenendijk and Stokhof (1984). Groenendijk (1999) proposes that logic be based on the principles of cooperative information exchange, instead of on principles of valid reasoning. Although I do not believe that logic should be based on anything specific, the proposal illustrates that there are various ways to formally study logical notions. 
To retain the "centrality of truth" (Davidson 1999) in the theory of meaning, one would have to explain away the common use of logical concepts to imperatives. The most obvious candidate for this is to say that two instructions are contradictory if the statement that both are fulfilled is a contradictory statement. Ironically, Ross' paradox, first introduced in objecting to the idea of a logic of imperatives, now figures as an obstacle for such a reduction. The theory I posted the letter, I posted the letter or I burned the letter $\}$ is not contradictory, but the set of instructions \{post the letter, post the letter or burn the letter\} is. Further differences between consistency of propositions and consistency of instructions can be given. Modus Tollens does not work for conditional imperatives, for example:

(38) a. If there is a pizza in the fridge, then there is beer in the fridge as well. There is no beer in the fridge, so there is no pizza in the fridge either.

b. \# If you see John tell him I said 'hi'. Don't say 'hi' to John, so you do not see him.

These observations seem to warrant an investigation into the 'logic' of imperatives in their own right.

Even if someone were to agree with all this, a crucial question is how to formalise such a logic of imperatives without reference to the concept of truth. Price (1994), for instance, backs down at this stage. ${ }^{16}$

If only we could justly retain familiar platitudes about validity, truth-functional connectives, and the like, without cutting ourselves off from the insights of non-factualism. (Price 1994, p. 142)

In view of this, Price proposes that we use the concept of 'truth' in a wide sense to retain uniformity in semantics, so as not to have to embark on "evasive manoeuvres" (idem) that make semantics more complex. As I hope to show in the final section, Update semantics Veltman (1996) offers a way of formalising the logic of imperatives without truth and propositions being the building blocks of the semantics. ${ }^{17}$ This may introduce unfamiliar elements into semantics and logic, but that this should not count as an objection was already argued by Beardsley (1944).

In several recent studies of imperative sentences the tendency to assimilate these sentences to indicatives has been marked. Although the desire to substitute a familiar and manageable form of expression for a form new to analysis and in some respects highly puzzling is highly understandable, nevertheless it is very difficult to accept any treatment of imperatives which fails to preserve their distinctive features. In common speech, imperatives are sui generis. It seems important to make a determined effort to analyse them as coordinate with, rather than subordinate to, indicatives. (Beardsley 1944, p. 175)

\footnotetext{
16 By 'non-factualism' Price means the view that not all meaningful language consists in the description of facts.

17 Forerunners of this framework are Stalnaker (1970), Hamblin (1971), Kamp (1981), Heim (1982) and Groenendijk and Stokhof (1991). Earlier proposals for an update semantic analysis of imperatives were developed by van der Torre and Tan (1998) and Zarnic (2002).
} 


\section{Update semantics for counterfactual imperatives}

\subsection{Update semantics}

In this section I will present a formal semantics for imperatives, including counterfactual imperatives, in the framework of update semantics. ${ }^{18}$ In update semantics Veltman (1996) we analyse the meaning of a sentential expression as a function that transforms an initial commitment slate into a new one, in which the message conveyed by the sentence (as it is used in some context) has somehow been incorporated. ${ }^{19}$ In the form of a slogan: You know the meaning of a sentence if you know the change it brings about in the commitment slate of anyone who accepts the message conveyed by it. ${ }^{20}$ The primary task of the semanticist is therefore to characterise commitment slates and the operations whereby one commitment slate is transformed into another.

Formally, the specification of an update system consists in the definition of three components: a formal language $\mathcal{L}$, a space $\mathcal{S}$ of possible commitment slates $S$ and a (recursive) definition of an update operation $[\varphi]: \mathcal{S} \rightarrow \mathcal{S}$ for every $\mathcal{L}$-expression $\varphi$. We can then write $S[\varphi]=S^{\prime}$, meaning that applying the operation $[\varphi]$ to commitment slate $S$ results in commitment slate $S^{\prime} .^{21}$

Instead of introducing entailment in the sense of truth preservation, the update semantic framework is centered around the notion of support of a sentence in a commitment slate. We say that $S$ supports $\varphi$, written $S \models \varphi$, if, and only if, $S[\varphi]=S$. In other words, a commitment slate supports some expression if accepting the message it conveys does not have any effect. Support is a notion that is meaningfully applied, not only to propositions, but also to issues raised by accepting a question and obligations undertaken by accepting commands. After having accepted the question 'Who will attend the meeting?' one's commitment slate supports the question 'Will John attend the meeting?'. The latter question is already on the table: any complete answer to the first question includes an answer to the second. Similarly, after having accepted the command 'Replace the hard disk' the command 'Remove the hard disk' is supported, because fulfilling the first command encompasses fulfilling the second.

Besides support we can appeal to various other 'mood-neutral' definitions of logical concepts. For instance, two $\mathcal{L}$-expressions are consistent if, and only if, there is a commitment slate such that we can update it with both expressions subsequently, without this resulting in an absurd commitment slate. A commitment slate can be called 'absurd' if the information it incorporates qualifies all possible states

\footnotetext{
18 The formalism presented here only deals with imperatives and specifically with counterfactual imperatives. See Nauze (2008) for an update semantics that incorporates not only imperatives but also performatively and descriptively used modal indicatives. That account goes some way into explaining the relationship between modality and performativity. I have nothing to say about that connection here.

19 The term 'commitment slate' is adopted from Hamblin (1971). Alternatively, semanticists use terms 'information state' or 'cognitive state' or '(deontic) scoreboard'.

20 This slogan is an adaptation of Veltman's.

21 We use a post-fix notation for the update operation, which naturally conforms with the left-to-right parsing of a text. That is, $S\left[\varphi_{1} ; \ldots ; \varphi_{n-1} ; \varphi_{n}\right]=\left(\ldots\left(S\left[\varphi_{1}\right]\right) \ldots\left[\varphi_{n-1}\right]\right)\left[\varphi_{n}\right]$.
} 
of affairs as impossible, or if the obligations it incorporates qualify all course of action prohibited. Just which commitment slates we consider to be absurd determines which expressions we consider to be contradictory, i.e. 'unacceptable'. Finally, an argument with premises $\varphi_{1} ; \ldots ; \varphi_{n}$ (in that specific order) to conclusion $\psi$ is said to be valid if, and only if, for all possible commitment slates $S$, after updating $S$ with $\varphi_{1} ; \ldots ; \varphi_{n}$ the resulting commitment slate supports $\psi .^{22}$

\subsection{Language, worlds and action plans}

The basic idea concerning imperatives and indicatives, as indicated in the introduction, is that propositions and instructions are treated on a par as basic semantic entities. The performative function of imperatives is explained in terms of the semantics of instructions as giving rise to new commitments to action, just as the performative function of indicatives is explained in terms of the semantics of propositions as expanding one's information (or commitment to things being thusand-so). ${ }^{23}$

Definition 1 (Syntax) We assume a finite set $I$ of instructions: $i, j, k, \ldots$, and a finite set $P$ of propositions: $p, q, r, \ldots$ The languages $\mathcal{L}_{P}, \mathcal{L}_{I}$ and $\mathcal{L}_{M}$ are defined as follows.

- $\mathcal{L}_{P}$ is the smallest set containing $P$ such that $\neg \varphi, \varphi \wedge \psi, \varphi \vee \psi \in \mathcal{L}_{P}$ for any $\varphi, \psi \in \mathcal{L}_{P}$.

$-\mathcal{L}_{I}$ is the smallest set containing $I$ such that $\neg l, \imath \wedge \eta, \imath \vee \eta \in \mathcal{L}_{I}$ for any $\imath, \eta \in \mathcal{L}_{I}$.

$-\mathcal{L}_{M}$ is the smallest set containing $\mathcal{L}_{P}$ and $\mathcal{L}_{I}$ such that $\varphi \Rightarrow \psi, \varphi \Rightarrow l$, was toch $\imath \in \mathcal{L}_{M}$ for any $\varphi, \psi \in \mathcal{L}_{P}$ and $\imath \in \mathcal{L}_{I}$.

The expressions $\varphi \Rightarrow \psi$ are indicative/subjunctive conditionals and the expressions $\varphi \Rightarrow l$ are conditional imperatives. The expressions of the form was toch $l$ are the counterfactual imperatives as we find them in Dutch. One may consider the performatively used English modal indicatives 'you should have such-and-so' to have the same semantic analysis.

To come to an interpretation of propositions and instructions, we look at the type of message they convey. For propositions, we can adopt the idea that they convey information about what the world is actually like. A possible world here is a valuation of atomic propositions as true or false. Accepting an instruction amounts to a change in one's practical commitments. These commitments are modelled by means of functions from worlds to a set of 'to do lists'. Here is an example of one to do list:

\footnotetext{
22 Veltman (1996) and van der Does et al. (1997) offer more detailed accounts and analysis of the update semantic framework.

23 Brandom's (1994) characterisation of 'normative pragmatics' in terms of 'scorekeeping rules', distinguishing 'doxastic commitment' from 'practical commitment' is roughly what is intended here. Unlike the more standard distinction between semantics and pragmatics that Brandom maintains, here we directly characterise the scoreboard changes as such in the semantics.
} 


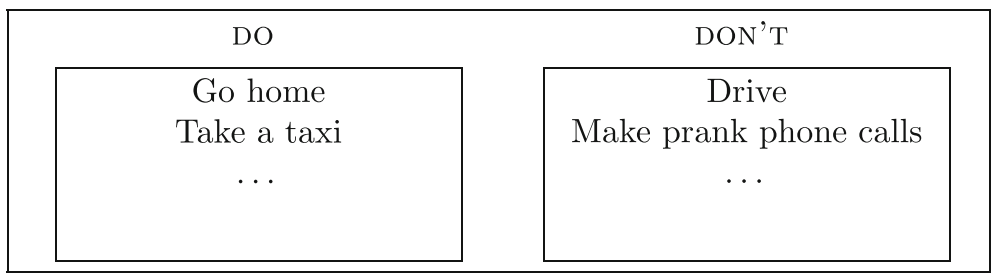

A set of to do lists is called an action plan [Compare the deontic plans in (Nauze 2008, pp. 183-184)]. It represents a choice between partial to do lists. Action plans figure in the semantics through practical commitments, i.e., a function mapping possible worlds to action plans, as seen in the diagram below. This practical commitment function determines what a person is required to do-in virtue of accepting instructions - in a given possible world: namely, to act in accordance with one of the to do lists in the action plan for that world. (So, an action plan is similar to a disjunctive normal form: the different to do lists are alternatives to choose between, and the different items on the to do list are cumulative.) The notion of practical commitment is not developed in detail in this paper. To give a rough idea of the notion, it will be assumed that every intentional action is the execution of (part of) an action plan. Note that not every change in practical commitments need be the result of accepting an instruction, i.e., as the outcome of a speech act. Likewise, in practice not every information update is the outcome of accepting some informative speech act.

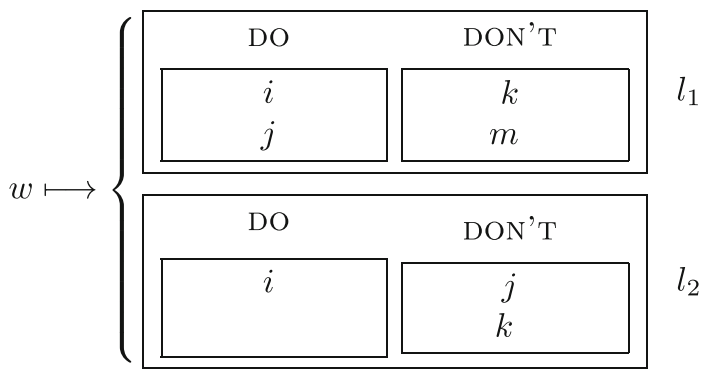

This diagram says that, conditional on $w$ being the actual state of affairs, its holder is committed to, either fulfilling instructions $i$ and $j$ and refraining from fulfilling $k$ and $m$, or fulfilling instruction $i$ and refraining from fulfilling $j$ and $k$. In other words, in $w$ he is committed to fulfil $i$ and refrain from fulfilling $k$, and if he decides to fulfil $j$ he is committed not to fulfil $m$. Accepting an instruction $n$ leads you to undertake a commitment to comply with $n$, placing it under 'do' in all of the to do lists for any world you hold (doxastically) possible. Accepting a negative instruction $\neg n$ amounts to rejecting the embedded instruction $n$, i.e., placing it on the 'don't' part. If the same instruction occurs on both the DO and the DON'T side of a single to do list, we call that list conflicting.

The functional dependency on possible worlds enables a straightforward formal representation of conditional obligations: if the instruction to stay at home is on the 
'do' side of all the to do lists in the action plan for every world where it is raining, then you have a conditional obligation to stay home if it is raining. An analysis of conditional imperatives is provided inter alia by the semantic framework presented hereafter.

Definition 2 (Worlds, to do lists, action plans and practical commitments)

- A world $w: P \rightarrow\{$ TRUE, FAlSE $\}$ is a complete function from propositions to truth values. $W$ is the set of all worlds.

- A to do list $l \subseteq(I \times\{\mathrm{DO}, \mathrm{DON}$ ' $\mathrm{T}\})$ is an assignment of 'do' and 'don't' to instructions. A to do list $l$ is conflicting iff for some $i \in I$ both $\langle i, \mathrm{DO}\rangle \in l$ and

$\langle i$, DON'T $\rangle \in l$. $L$ is the set of all to do lists.

- An action plan $\alpha \subseteq L$ is a set of to do lists. Given two action plans $\alpha$ and $\beta$, their product is $\alpha \sqcap \beta=\left\{l_{1} \cup l_{2} \mid l_{1} \in \alpha \& l_{2} \in \beta\right\}$. The set of all action plans is Pow $(L)$.

- A practical commitment function $R: W \rightarrow \mathcal{P}$ ow $(L)$ assigns an action plan to each world. A practical commitment function is practically coherent iff it is non-empty and for all worlds $w, R(w)$ does not contain conflicting to do lists.

An action plan tells us what we intend to do and what we intend to refrain from. There may be a degree of undecidedness in our action plans. For instance, we may intend to go to the beach either by car or by train. This action plan is represented in our semantics as a set of two to do lists: the first list reads "go to the beach; take the car', the second list reads "go to the beach; take the train',. The null to do list $\emptyset$ is an empty list: " "'; the null action plan is the set containing only the null to do list, so $\{\emptyset\}$.

The following definition gives us the minimal fact sheet and action plan for a Boolean complex of propositions or instructions, respectively.

Definition 3 (Minimal fact sheet and minimal action plan) To each $\mathcal{L}_{P}$-expression corresponds a minimal fact sheet and to each $\mathcal{L}_{I}$-expression corresponds a minimal action plan.

$$
\begin{aligned}
\|p\| & =\{w \mid w(p)=\mathrm{TRUE}\} & \|i\| & =\{\{\langle i, \mathrm{DO}\rangle\}\} \\
\|\neg p\| & =\{w \mid w(p)=\mathrm{FALSE}\} & \|\neg i\| & =\{\{\langle i, \mathrm{DONT}\rangle\}\} \\
\|\varphi \vee \psi\| & =\|\varphi\| \cup\|\psi\| & \|l \vee \eta\| & =\|l\| \cup\|\eta\| \\
\|\neg(\varphi \vee \psi)\| & =\|\neg \varphi\| \cap\|\neg \psi\| & \|\neg(l \vee \eta)\| & =\|\neg l\| \sqcap\|\neg \eta\| \\
\|\varphi \wedge \psi\| & =\|\varphi\| \cap\|\psi\| & \|l \wedge \eta\| & =\|l\| \sqcap\|\eta\| \\
\|\neg(\varphi \wedge \psi)\| & =\|\neg \varphi\| \cup\|\neg \psi\| & \|\neg(l \wedge \eta)\| & =\|\neg l\| \cup\|\neg \eta\|
\end{aligned}
$$

The minimal fact sheets are just the classical 'propositions'. Breaking with the symmetry with minimal action plans, we may equally formulate the minimal fact sheet of a negation $\|\neg \varphi\|$ as $W \backslash\|\varphi\|$.

\subsection{Results and consequences}

A useful distinction in theories of action is that between the intrinsic result of an action and its extrinsic, causal consequences (see von Wright 1971). For instance, 
the result of opening the window is the window's opening, or its being open. And the result of the raising of your arm (or: the result of fulfilling the instruction "raise your arm'”) is the rising of your arm. A possible consequence of opening the window is a gush of wind and, perhaps, the blowing away of sheets of paper on your desk. Note that the consequences of your actions are simply the (causal) consequences of the results of your actions: the blowing away of the sheets is a causal effect of the window's opening. These concepts will be useful in a semantic analysis of counterfactual conditionals and counterfactual imperatives. ${ }^{24}$

Definition 4 (Result) The function $\rho: I \rightarrow \mathcal{P} o w(W)$ characterises the result of fulfilling a positive practical commitment $\langle i$, DO $\rangle$. The result of fulfilling a negative practical commitment $\langle i$, DON'T $\rangle$ is $(W \backslash \rho(i))$. The result of complying with a to do list $l$ is the intersection of the results of fulfilling the practical commitments in $l$. The result of executing an action plan $\alpha$ is the union of the results of complying with the to do lists in $\alpha$.

Executing an action plan means fully complying with one of the alternatives it allows for, i.e., with one of the to do lists in it. The formula $\rho(\alpha)$ is a shorthand notation for the set of worlds consistent with the fulfilment of the action plan $\alpha$.

A simplification of this account would be to assume that for every instruction $i \in I$ there exists a proposition $r_{i} \in P$ such that $\rho(i)=\left\{w \in W \mid w\left(r_{i}\right)=\right.$ TRUE $\}$. In that case, for every instruction, e.g. "open the window", there would be a proposition expressing the result of the action ordered, i.e. "the window is open'". This would account for the intuition of a 'shared content' of imperatives and corresponding indicatives, as mentioned in the introduction.

The consequences of a state of affairs in a world are not logically determined by the world and the state of affairs. They are learned by gathering information, and we express our commitment to the characteristics of this function by making counterfactual conditional statements: If I had opened the window, the sheets would have blown away. Therefore, accepting a counterfactual conditional will amount to undertaking further commitments concerning the consequences of certain states of affairs (or actions).

Definition 5 (Consequence) The consequences of some state of affairs $X \subseteq W$ in a world $w \in W$ are represented by a function $E:(W \times \mathcal{P} o w(W)) \rightarrow \mathcal{P} o w(W)$. $E$ is causally coherent iff $E(w, X) \neq \emptyset, w \in E(w, X \cup\{w\})$, and $E(w, X) \subseteq X$, for all $w \in W$ and $X \subseteq W$.

The concept of a consequence function is rather abstract. It is somewhat similar to Lewis's (1979) notion of a 'miracle': if we would revise the world $w$ so that it would be a member of set $X$, it would have to be a world in the subset $E(w, X) \subseteq X$. For instance, if we change $w$ so that it is a member of the set of worlds where Nixon presses the button, then $w$ has to be a member of the set of worlds in which there is a nuclear war. Naturally, then, $E(w, X)$ is not empty, $w$ is itself possible given the

\footnotetext{
${ }^{24}$ As indicated earlier, I abstract away from issues concerning the subject of imperatives, the way it is addressed. If we would introduce this aspect, then the results should be further qualified with reference to the person fulfilling the instruction.
} 
consequences of some actually obtaining state of affairs in $w$, and every state of affairs is part of its own consequences. ${ }^{25}$

The function $E$ is defined in such a way that it represents consequences of both factual and counterfactual states of affairs. If $w$ is already a member of the set $X$, then $E(w, X)$ informs us, not of some counterfactual necessity, but of an actual one: it tells us that $w$ 's being a member of $E(w, X)$ is a consequence of its being a member of $X$. In subsection 6.6 below, a more concrete representation of this notion is sketched.

\subsection{Commitment slates and updates}

Communication is a diverse activity: we gather information by accepting the simple assertions of others, we undertake practical commitments by promising or by accepting instructions from others, we assign responsibility by attributing causal consequences to actions, events and so on. The meaning of these communicative activities can be characterised by means of changes in one's commitment slate (scoreboard, cognitive state). The diversity of communicative acts requires that we represent commitment slates equally diverse. We have, first of all, a 'fact sheet' $F \subseteq W$ on which our factual commitments (on-record beliefs, accepted information) are listed. This fact sheet is formally represented by a set of worlds: namely, those worlds that are consistent with one's factual commitments. Second of all, there are practical commitments: accepted instructions. They are formally represented by practical commitment functions $R: W \rightarrow \mathcal{P}$ ow $(L)$. These functions also range over the worlds that are excluded by one's factual commitments, in order to account for counterfactual imperatives as well. Third and last, there are causal dependency commitments, which we undertake by accepting certain causal conditionals. They are formally represented by consequence functions $E$, as defined above. A commitment slate combines these elements into a single 'scoreboard'.

Definition 6 (Commitment slate) A commitment slate $S=\left\langle F_{S}, R_{S}, E_{S}\right\rangle$ is a triple, where $F_{S} \subseteq W$ is a fact sheet, $R_{S}: W \rightarrow \mathcal{P} o w(L)$ is a practical commitment function and $E_{S}$ is a consequence function. The blank commitment slate 1 is $\left\langle F_{1}, R_{1}, E_{1}\right\rangle$, where $F_{1}=W, R_{1}(w)=\{\emptyset\}$ for all $w \in W$, and $E_{1}(w, X)=X$ for all $w \in W$ and $X \subseteq W$.

A commitment slate $S$ is consistent iff $F_{S}$ is non-empty, $R_{S}$ is practically coherent, and $E_{S}$ is causally coherent. The set of inconsistent commitment slates is labelled $\Lambda$.

Consistency of a commitment slate requires three things: you do not have contradictory factual commitments; your practical commitments are practically coherent; and your causal commitments are coherent. The inconsistent slates $\Lambda$ are considered

\footnotetext{
25 As defined here, no monotonicity conditions are imposed on consequence functions. They could be added here, requiring also that we modify the definition of commitment change below, to make updates preserve the monotonicity conditions.
} 
to be 'terminal' slates in the update practice: those slates require 'repair' before one can continue sensibly with updating. ${ }^{26}$

On the basis of the definition of commitment slates we can now spell out, first, what it means to incorporate new practical and causal commitments and, second, what it means to retract information from one's fact sheet.

Definition 7 (Commitment change) Let $S$ be a commitment slate. The incorporation of a practical commitment to $l$ in a world is $R_{S} \otimes\|l\|$ and the incorporation of a causal commitment to $\psi$ being a consequence of $\varphi$ in a world is $E_{S} \otimes_{\|\varphi\|}\|\psi\|$.

$$
\begin{aligned}
& R_{S} \otimes\|\imath\|= \begin{cases}w \mapsto\left(R_{S}(w) \sqcap\|\imath\|\right), & \text { if } w \in F_{S} \\
w \mapsto R_{S}(w), & \text { otherwise }\end{cases} \\
& E_{S} \otimes_{\|\varphi\|}\|\psi\|= \begin{cases}(w, X) \mapsto\left(E_{S}(w, X) \cap\|\psi\|\right), & \text { if } w \in F_{S} \text { and } X=\|\varphi\| \\
(w, X) \mapsto E_{S}(w, X), & \text { otherwise }\end{cases}
\end{aligned}
$$

Retracting information from one's fact sheet leads to the (re)introduction of some possible worlds. The reasons for such a retraction differ from one occasion to the next. One reason is the consideration of non-actual possibilities in the evaluation of a counterfactual conditional. Another reason is the (re)consideration of past choices other than one's actual decision. The latter species of retraction is invoked in the analysis of counterfactual imperatives. Accordingly, we define the retraction operation by means of two clauses: one for retracting propositions and another one for retracting (the result of fulfilling) practical commitments from one's factual information. ${ }^{27}$

Definition 8 (Retraction) Let $S$ be a commitment slate, $\varphi \in \mathcal{L}_{P}$ and $\imath \in \mathcal{L}_{I}$. The retraction of $\varphi$ from $S$ is $S \downarrow \varphi$ and the retraction of $\imath$ from $S$ is $S \downarrow l$. This does not change the practical commitment and consequence functions: $R_{S \downarrow \varphi}=R_{S \downarrow l}=$ $R_{S}, E_{S \downarrow \varphi}=E_{S \downarrow l}=E_{S}$. The retractions do change the fact sheets.

$$
\begin{aligned}
F_{S \downarrow \varphi} & =F_{S} \cup\left\{w \mid w \in E_{S}(v,\|\neg \varphi\|) \text { for some } v \in F_{S}\right\} \\
F_{S \downarrow \downarrow} & =F_{S} \cup\left\{w \mid w \in E_{S}(v, \rho(\|\neg l\|)) \text { for some } v \in F_{S}\right\}
\end{aligned}
$$

Now we can define the updates on commitment slates themselves.

Definition 9 (Update) Let $\varphi$ and $\psi$ be $\mathcal{L}_{P}$-expressions and let $\imath$ be an $\mathcal{L}_{I}$-expression. The update of a commitment slate $S$ with a $\mathcal{L}_{M}$-expression is defined as follows.

$$
\begin{aligned}
S[\varphi] & =\left\langle F_{S} \cap\|\varphi\|, R_{S}, E_{S}\right\rangle \\
S[l] & =\left\langle F_{S}, R_{S} \otimes\|\imath\|, E_{S}\right\rangle \\
S[\varphi \Rightarrow \psi] & =\left\langle F_{S}, R_{S}, E_{(S \downarrow \neg \varphi)} \otimes_{\|\varphi\| \|}\|\psi\|\right\rangle \\
S[\varphi \Rightarrow l] & =\left\langle F_{S}, R_{(S \downarrow \neg \varphi)[\varphi][l]}, E_{S}\right\rangle \\
S[\text { was toch } l] & =\left\langle F_{S}, R_{(S \downarrow \neg l)[l]}, E_{S}\right\rangle
\end{aligned}
$$

\footnotetext{
26 I follow Nauze (2008, p. 186) in defining a set of inconsistent slates $\Lambda$, rather than following Veltman (1996) in defining a single 'absurd' commitment slate and requiring all commitment slates to be either consistent or 'go to absurdity'.

27 See Veltman (2005) for a definition of retraction based on a distinction between factually possible and counterfactually possible worlds.
} 


\subsection{Discussion of some examples}

The retraction operations are used in the analysis of conditionals. They do not lead to a genuine retraction of information in $F_{S}$, but they only set up the right context in which we update with the consequent of the conditional. Let me give an example of a counterfactual conditional. Suppose we have accepted that it does not rain and that the streets are not wet, so $S=\mathbf{1}[\neg$ rain $][\neg$ wet $]$. In this context $F_{S}$ contains some information, but $R_{S}=R_{1}$ and $E_{S}=E_{1}$ are still trivial. Now we update with the counterfactual "If it were raining, the streets would be wet', i.e., rain $\Rightarrow$ wet. This means that we have to compute $E_{(S \downarrow \neg \text { rain })} \otimes_{\| \text {rain } \|} \|$ wet $\|$. We start with determining $S^{\prime}=S \downarrow \neg$ rain. As the definition of retraction shows, the only aspect of $S$ that changes as a result of the retraction is the fact sheet: $F_{S^{\prime}}$ combines the worlds in which it does not rain and the streets are not wet, i.e., the worlds in $F_{S}$, with the worlds that are the possible consequence of rain in $F_{S}$ worlds, i.e., the worlds in $E_{S}(w, \|$ rain $\|)$ for $w \in F_{S}$. Because $E_{S}$ is still trivial, $E_{S}(w, \|$ rain $\|)=\|$ rain $\|$ for all $w$. So, $F_{S^{\prime}}=F_{S} \cup \|$ rain $\|$. Relative to this slate $S^{\prime}$, we update $E_{S^{\prime}}=E_{S}$ as follows: $E_{S^{\prime}} \otimes_{\| \text {rain } \|} \|$ wet $\|$. For worlds not in $F_{S^{\prime}}$ this does not have an effect. But for the worlds $w$ in $F_{S^{\prime}}$ it does: from $E_{S^{\prime}}(w, \|$ rain $\|)$ we exclude all those worlds that do not belong to $\|$ wet $\|$. In other words, we accept that in such worlds, the consequence of it raining would be that the streets are wet.

The analysis of counterfactual imperatives also involves retraction. Let us take the example "Was toch thuisgebleven" (you should have stayed at home). By assumption (conversational pragmatics), the context in which we update with the counterfactual imperatives is one in which it is an established fact that the addressee did not stay. So,

$$
F_{S} \cap \rho(\text { stay })=\emptyset .
$$

Moreover, we may assume that this not-staying was an intentional refraining to stay, so that in fact the action plan was not to stay, so $\langle$ stay, DON'T $\rangle \in R_{S}(w)$, at least for all the $w \in F_{S}$. Consequently, we cannot simply update with the imperative 'Stay', because it would result in an practically incoherent practical commitment function-hence, an inconsistent commitment slate. Therefore, we need to retract the commitment not to stay.

First we expand this fact sheet $F_{S}$, hypothetically, to include those worlds $w$ that are 'what some $F_{S}$-possible world $v$ would be like if the practical commitment $\langle$ stay, Do) had been fulfilled':

$$
F_{S \downarrow \neg s t a y}=F_{S} \cup\left\{w \mid w \in E_{S}(v, \rho(\| \text { stay } \|)) \text { for some } v \in F_{S}\right\} .
$$

Relatively to this hypothetical fact sheet, we update the practical commitment function $R_{(S \downarrow \neg s t a y)}$ (which is just the same as $R_{S}$ ) according to Definition 7 . We add the practical commitment to stay to the plan for each world $w$ in the fact sheet.

$$
R_{(S \downarrow \neg \text { stay })} \otimes \| \text { stay } \|= \begin{cases}w \longmapsto\left(R_{(S \downarrow \neg \text { stay })}(w) \sqcap \| \text { stay } \|\right), & \text { if } w \in F_{(S \downarrow \neg \text { stay })} \\ w \longmapsto R_{(S \downarrow \neg \text { stay })}(w), & \text { otherwise }\end{cases}
$$


In view of the hypothetical addition to the fact sheet, this practical commitment change includes an additional practical commitment for those worlds that could have been the actual one given that the practical commitment to stay were (made and) fulfilled. In short, what is added is a commitment to stay, for all possible worlds, both real and hypothetical.

In general, if we have a (positive) practical commitment $i$ for some action in a given world $w$, then that commitment will be executed so, after the action is performed, it will typically be the case that $F_{S} \subseteq \rho(i)$. After all, we normally execute the plans we make, or change our plans. The update with counterfactual imperatives creates a divergence between our practical and factual commitments. Now we have a factual commitment that we didn't stay, combined with an after-the-fact commitment to stay. Understanding the relevance is of such an after-the-fact divergence is not the aim of this paper. The same question can be asked for counterfactual conditionals. There, a natural idea that counterfactual conditionals are informative insofar as they are the implicates of laws of nature. Similarly, counterfactual imperatives can be practically relevant insofar as they are expressive of character, or more concretely, of a person's laws of conduct, i.e. personal ethics.

Using the update definition we can also see how Ross' problem is avoided. If we accept a disjunctive imperative $i \vee j$, e.g., "post the letter or burn it", then a subsequent update with the imperative 'don't burn the letter' leads to the introduction of conflicting to do lists and, hence, to the absurd commitment slate. Let $S_{1}=\mathbf{1}[i \vee j]$ and $S_{2}=S_{1}[\neg i]$. Then $R_{S_{1}}$ is such that for all $w, R_{S_{1}}(w)=\|i \vee j\|=$ $\{\{\langle i, \mathrm{DO}\rangle\},\{\langle j, \mathrm{DO}\rangle\}\}$. Now if we could continue by updating with $\neg i$, then $R_{S_{2}}$ would be such that for all $w, R_{S_{2}}(w)=\|i \vee j\| \sqcap\|\neg i\|=(\|i\| \cup\|j\|) \sqcap\|\neg i\|=$ $\|i \wedge \neg i\| \cup\|j \wedge \neg i\|=\{\{\langle i$, DO $\rangle,\langle i$, DON'T $\rangle\},\{\langle j$, DO $\rangle,\langle i$, DON'T $\rangle\}\}$. This plan consists of two to do lists, one of which is conflicting. Consequently, $S_{2}$ would not be consistent. According to the definition of the updates, this means that in fact $S_{2} \in \Lambda$, the set of inconsistent states.

This incompatibility of $i \vee j$ and $\neg i$ does not mean that it is pragmatically impossible to deal with such instructions. It merely makes the semantic point that after the acceptance of $i \vee j$, the acceptance of $\neg i$ has to be construed as a revision of one's commitments, whereby an accepted practical commitment-i.e., the commitment to a choice between $i$ and $j$-is (implicitly) retracted. To keep your different authorities happy, you might have to revise your practical commitments in this way. But in certain cases you might protest to the second instruction on the basis of its incompatibility with the first. For instance, to your father's instruction "Do your homework" you might reply "But mom told me to either do my homework or to clean up my room; and I'm cleaning up now'.

With these definitions in place, we have now given a formal semantic analysis of imperatives that does not attribute a 'propositional content' to them. Facts and tasks are different matters. Taking their difference seriously allows us to develop a semantic analysis of complex imperatives and to avoid the problems with disjunctive imperatives noticed by Ross. The analysis presented here does not only account for simple, atomic instructions such as 'Go home' or 'Open the window', but also disjunctive ones and for the counterfactual instructions found in Dutch. I hope the reader will be convinced that the framework can be extended to other 
cases, such as first and third person imperatives. Possibly, certain deontic modal expressions could be analysed in terms of this framework as well (see Nauze 2008). But of course that all still needs to be shown. Before concluding, I would like to consider one possible amendment for the presented framework, indicating the possibility of a tighter connection between counterfactuals and time-dependent possibility.

\subsection{A temporal analysis for consequence functions}

Many semantic analyses of counterfactual conditionals make crucial reference to temporal concepts (see, for instance Condoravdi 2002). Others have preferred nontemporal semantic analyses of counterfactual conditionals (Lewis 1979; Veltman 2005). The semantic analysis presented above does not involve any explicit reference to time. It has intentionally been left abstract, to allow for a certain degree of modularity: depending on one's view of counterfactual semantics, the consequence function can be detailed in different ways. Unfortunately, it makes the consequence functions here also somewhat oblique. To give more insight in the concept, the following is an outline of a temporally explicit version of the account given above.

Let $\mathcal{T}$ be a set of ordered times (or intervals). We assume that for every time $t$ there is an equivalence relation $\simeq_{t} \subseteq W \times W$, where $w \simeq_{t} v$ should have the meaning that worlds $w$ and $v$ are similar up to, and including, time $t$. (If we add a notion of 'event time' for atomic propositions, we might define this relation by saying that $w$ and $v$ agree on all propositions with an event time $t$ or earlier.) Furthermore, given a set of physically possible worlds Phys $\subseteq W$, the physically possible continuations of $w$ after a time $t$ would be those worlds $v$ that are physically possible $(v \in$ Phys $)$ and equivalent to $w$ up to $t\left(v \simeq_{t} w\right)$. Now, given any set of worlds $X$, we assume that there is a unique latest time $t_{X}$ such that $w \simeq_{t_{X}} v$ for all worlds $v$ and $w$ in $X$ (so $t_{X}$ is the latest time for which $X$ is a $\simeq$-equivalence class). The set $E(w, X)$ can now be defined as consisting of all physically possible continuations of $w$ after $t_{X \cup\{w\}}$ that are members of $X$.

To define retraction, we adopt the following definitions. World $v$ is a closest $X$-alternative to $w$ if, and only if, (i) $w$ and $v$ are both physically possible, (ii) $w \notin X$ and $v \in X$ and (iii) for all times $t$, if $w \simeq_{t} u$ for some $u \in X$, then $w \simeq_{t} v$ as well. Now we set $F_{S \downarrow X}=\left\{w \mid w\right.$ is a closest $(W \backslash X)$-alternative to some $\left.v \in F_{S}\right\}$, where $X$ can be $\|\varphi\|$ or $\rho(\|l\|)$.

Using the reduction of the consequence relation $E$ to the set of physically possible worlds Phys naturally leads us to replace the commitment slate parameter for $E$ by a commitment slate parameter $P h y s_{S}$. Rather than changing $E$ as a result of updating with counterfactual conditionals, we now make changes in Phys. The update of commitment slate $S$ with $\varphi \Rightarrow \psi$ would change this parameter: Phys $_{S[\varphi \Rightarrow \psi]}=\left(\right.$ Phys $\left._{S} \backslash F_{(S \downarrow \neg \varphi)[\varphi][\neg \psi]}\right)$. It tells us that, from all the closest $\varphi$-alternatives to the worlds in $F_{S}$, the $\neg \psi$ worlds are physically impossible.

Perhaps, with this more explicit temporal semantic analysis it will also be possible to provide a decompositional semantics of the was toch operator, involving a tense operator (expressed by the past participle construction) shifting the event time to the past and a modal or irrealis operator (expressed by the past tense) for the 
retraction of the fact that the action as 'commanded' has not been performed from $F_{S}$. Such a development of the proposal would require a more detailed analysis of tense and modality in general and will have to await another occasion.

\section{Concluding remarks}

The main purpose of this paper was to argue for an approach to the semantics of imperatives which does not involve a separation between a 'propositional content' and a mood indicator or illocutionary force operator. Instead, instructions are taken to be irreducible semantic entities, just as propositions-truth value carrying expressions - are commonly taken to be semantically primitive. First, three different types of reductive approaches to imperatives were distinguished and arguments against each of them were offered. The first two face conceptual problems, but the third has empirical problems: the cases of third person imperatives, counterfactual imperatives and the different logical behaviour of disjunction in imperatives. Update semantics has been presented as a framework for dealing with these problems: it makes no use of a distinction between content and force but interprets the imperatives directly as instructions, which are represented in the semantics as update functions that transform one commitment slate into another commitment slate. Instructions can be combined into larger wholes and embedded under 'modal' operators, such as the counterfactual 'was toch' operator. The semantic analysis of the latter construction constitutes a faithful interpretation of the counterfactual imperative in Dutch. Thereby I hope to have shown that the emancipation of imperatives in natural language semantics is not only a good linguistic idea, but that it is also theoretically sound and formally feasible.

Acknowledgments This paper has been a long time in the making. For many valuable comments many thanks are due to Frank Veltman, Martin Stokhof, Paul Dekker, Fabrice Nauze, Darrin Hindsill, Henk Wolf, Hans Bennis, Nicholas Asher, Maria Aloni, Magdalena Schwager, Ede Zimmermann, Herman Philipse, Albert Visser, and the reviewers of Linguistics and Philosophy.

Open Access This article is distributed under the terms of the Creative Commons Attribution Noncommercial License which permits any noncommercial use, distribution, and reproduction in any medium, provided the original author(s) and source are credited.

\section{References}

Aloni, M. (2005). Utility and implicatures of imperatives. In Proceedings of DIALOR'05, Loria, Nancy, France.

Austin, J. L. (1956/1979). Performative utterances. Transcript of a talk for B.B.C. radio. In J. O. Urmson \& G. J. Warnock (Eds.), Philosophical papers (3rd ed., pp. 233-252). Oxford: Clarendon Press.

Bach, K. (1975). Performatives are statements too. Philosophical Studies, 28, 229-236.

Beardsley, E. L. (1944). Imperative sentences in relation to indicatives. Philosophical Review, 53, $175-185$.

Belnap, N. (1990). Declaratives are not enough. Philosophical Studies, 59(1), 1-30.

Bennis, H. (2006). Agreement, pro and imperatives. In P. Ackema, P. Brandt, M. Schoorlemmer, \& F. Weerman (Eds.), Arguments and agreement (pp. 101-127). Oxford: Oxford University Press. 
Beukema, F., \& Coopmans, P. (1989) A government-binding perspective on the imperative in English. Journal of Linguistics, 25, 417-436.

Bolinger, D. (1977). Meaning and form. London: Longman.

Brandom, R. (1994). Making it explicit: Reasoning, representing, and discursive commitment. Cambridge, MA: Harvard University Press.

Chomsky, N. (1975). The logical structure of linguistic theory. New York: Plenum Press.

Condoravdi, C. (2002). Temporal interpretation of modals: Modals for the present and modals for the past. In D. Beaver, S. Kaufmann, B. Clark, \& L. Casillas (Eds.), The construction of meaning (pp. 59-88). Stanford: CSLI Publications.

Davidson, D. (1979). Moods and performances. In A. Margalit (Ed.), Meaning and use (pp. 9-20). Berlin: Springer.

Davidson, D. (1999). The centrality of truth. In J. Peregrin (Ed.), Truth and its nature (if any) (pp. 105115). Dordrecht: Kluwer.

Frege, G. (1879). Begriffsschrift. Halle a. S.: L. Nebert

Frege, G. (1918). Der Gedanke. Eine logische Untersuchung. Beiträge zur Philosophie des deutschen Idealismus, 2, 58-77.

Geurts, B. (2005). Entertaining alternatives: Disjunctions as modals. Natural Language Semantics, 13, 383-410

Groenendijk, J. (1999). The logic of interrogation: Classical version. In T. Matthews \& D. Strolovitch (Eds.), Proceedings of SALT IX. CLC Publications: Santa Cruz.

Groenendijk, J., \& Stokhof, M. (1984). Studies on the semantics of questions and the pragmatics of answers. Ph.D. thesis, Universiteit van Amsterdam.

Groenendijk, J., \& Stokhof, M. (1991). Dynamic predicate logic. Linguistics and Philosophy, 14(1), 39-100.

Groenendijk, J., \& Stokhof, M. (1997). Questions. In J. van Benthem \& A. ter Meulen (Eds.), Handbook of logic and language (pp. 1055-1124). Amsterdam/Cambridge, MA: Elsevier/MIT Press.

Haeseryn, W., Romijn, K., Geerts, G., de Rooij, J., \& van den Toorn, M. (Eds). (1997). Algemene Nederlandse Spraakkunst. Groningen/Deurne: Martinus Nijhoffuitgevers/Wolters Plantyn.

Hamblin, C. L. (1971). Mathematical models of dialogue. Theoria, 37, 130-155.

Hamblin, C. L. (1987). Imperatives. Oxford: Basil Blackwell.

Han, C. (1998). The structure and interpretation of imperatives: Mood and force in universal grammar. Ph.D. thesis, University of Pennsylvania.

Han, C. (1999). Deontic modality, lexical aspect and the semantics of imperatives. In Linguistics in Morning Calm 4. Seoul: Hanshin Publications

Hare, R. M. (1949). Imperative sentences. Mind, 58, 21-39.

Hausser, R. (1978). Surface compositionality and the semantics of mood. manuscript. München: Wilhelm Fink.

Heim, I. (1982). The semantics of definite and indefinite noun phrases. Ph.D. thesis, University of Massachusetts, Amherst

Hofstadter, A., \& McKinsey, J. (1939). On the logic of imperatives. Philosophy of Science, 6, 446-457. Huntley, M. (1984). The semantics of English imperatives. Linguistics and Philosophy, 7, 103-134.

Jorgensen, J. (1938). Imperatives and logic. Erkenntnis, 7, 288-298.

Kamp, H. (1973). Free choice permission. Proceeding of the Aristotelian Society, 74, 57-74.

Kamp, H. (1979). Semantics versus pragmatics. In F. Guenther \& S. J. Schmidt (Eds.), Formal semantics and pragmatics for natural languages. Dordrecht: Reidel.

Kamp, H. (1981). A theory of truth and semantic representation. In J. Groenendijk, T. Janssen, \& M. Stokhof (Eds.), Formal methods in the study of language (pp. 277-322). Amsterdam: Mathematisch Centrum.

Katz, J. J. (1977). Propositional structure and illocutionary force. New York: The Harvester Press.

Katz, J. J., \& P. M. Postal (1964). An integrated theory of linguistic descriptions. Cambridge, MA: MIT Press.

Kenny, A. J. (1963). Practical inference. Analysis, 26(3), 65-75.

Lakoff, G. (1972). Linguistics and natural logic. In D. D. G. Harman (Eds.), Semantics of natural language. Dordrecht: Reidel.

Lewis, D. K. (1972). General semantics. In D. Davidson \& G. Harman (Eds.), Semantics of natural language (pp. 169-218). Dordrecht: D. Reidel.

Lewis, D. K. (1979). Counterfactual dependence and time's arrow. Noûs, 13(4), 455-476.

Mally, E. (1926). Grundgesetze des Sollens. Elemente der Logik des Willens. Graz: Leuschner \& Lubensky.

Mastop, R. (2005). What can you do? Ph.D. thesis, ILLC, Amsterdam. 
McGinn, C. (1977). Semantics for nonindicative sentences. Philosophical Studies, 32, 301-311.

Nauze, F. D. (2008). Modality in typological perspective. Ph.D. thesis, ILLC, University of Amsterdam. Ninan, D. (2005). Two puzzles about deontic necessity. In J. Gajewski, V. Hacquard, B. Nickel, \& S. Yalcin (Eds.), New work on modality. Cambridge, MA: MITWPL 51.

Platzack, C., \& Rosengren, I. (1998). On the subject of imperatives: A minimalist account of the imperative clause. The Journal of Comparative Germanic Linguistics, 1(3), 177-224.

Portner, P. (1997). The semantics of mood, complementation, and conversational force. Natural Language Semantics, 5, 167-212.

Portner, P. (2005). The semantics of imperatives within a theory of clause types. In K. Watanabe \& R. B. Young (Eds.), Proceedings of semantics and linguistic theory (Vol 14). Ithaca, NY: CLC Publications.

Price, H. (1994). Semantic minimalism and the Frege point. In S. L. Tsohatzidis (Ed.), Foundations of speech act theory: Philosophical and linguistic perspectives (pp. 132-155). London: Routledge

Ross, A. (1941). Imperatives and logic. Theoria, 25(7), 53-71.

Ross, J. R. (1970). On declarative sentences. In R. A. Jacobs \& P. S. Rosenbaum (Eds.), Readings in English transformational grammar (pp. 222-272). Waltham, MA: Ginn.

Schmerling, S. F. (1975). Imperative subject deletion and some related matters. Linguistic Inquiry, 6, 501-510.

Schmerling, S. F. (1982). How imperatives are special and how they aren't. In R. Schneider, K. Tuite, \& R. Chametzky (Eds.), Papers from the parasession on nondeclaratives (pp. 93-106). Chicago: Chicago Linguistics Society.

Schwager, M. (2006). Interpreting imperatives. Ph.D. thesis, Johann Wolfgang Goethe-Universität Frankfurt a.M.

Searle, J. R. (1969). Speech acts. Cambridge: Cambridge University Press.

Stalnaker, R. C. (1970). Pragmatics. Synthese, 22(1-2), 272-289.

Stenius, E. (1967). Mood and language-game. Synthese, 17, 254-274.

Stowell, T. (1982). On tense in infinitives. Linguistic Inquiry, 13, 561-670.

van der Torre, L., \& Tan, Y. H. (1998). An update semantics for deontic reasoning. In Proceedings of DEON'98 (pp. 409-426)

van der Auwera, J., Dobrushina, N., \& Goussev, V. (2003). A semantic map for imperative-hortatives. In D. Willems, T. Colleman, \& B. Defrancq (Eds.), Points of comparison in linguistics: From morphology to discourse. Basingstoke: Palgrave Macmillan.

van der Does, J., Groeneveld, W., \& Veltman, F. (1997) An update on “'might'. Journal of Logic Language and Information, 6(4), 361-380.

Veltman, F. (1996). Defaults in update semantics. Journal of Philosophical Logic, 25, 221-261.

Veltman, F. (2005). Making counterfactual assumptions. Journal of Semantics, 22, 159-180.

von Wright, G. H. (1957). Logical studies. London: Routledge and Kegan Paul.

von Wright, G. H. (1971). Explanation and understanding. London: Routledge \& Kegan Paul.

von Wright, G. H. (1996). Is there a logic of norms? In Six essays in philosophical logic (pp. 35-54). Helsinki: Societas Philosophica Fennica.

Wittgenstein, L. (1953). Philosophische Untersuchungen. Oxford: Blackwell.

Wolf, H. (2003). Imperatieven in de verleden tijd. Taal \& Tongval, 55, 168-187.

Zarnic B (2002) Dynamic semantics, imperative logic and propositional attitudes. Uppsala prints and preprints in philosophy, Uppsala Universitet 